\title{
INTENSITAS インテンシティーDILIHAT DARI KONTEKS EMOTIF DAN TUJUAN KOMUNIKASI DALAM TINDAK KOMUNIKASI PADA DRAMA GREAT TEACHER ONIZUKA REMAKE KARYA IMAI KAZUHISA
}

\author{
Masilva Raynox Mae \\ Sekolah Menengah Atas Trimurti Surabaya
}

\begin{abstract}
Abstrak: Intensitas atau penekanan ujaran sering digunakan manusia dalam tindak komunikasi, tetapi hal itu sering tidak disadari. Intensitas biasa digunakan untuk lebih menarik perhatian lawan tutur. Penutur menggunakan intensitas dengan harapan lawan tutur dapat lebih memahami maksud dari yang disampaikan. Oleh karena itu, penggunaan intensitas dalam sebuah tindak komunikasi pun tidak akan lepas dari konteks emotif yang melatarbelakangi terjadinya tindak komunikasi tersebut. Penelitian ini dilakukan untuk mengetahui (1) bagaimana fungsi konteks emotif intensitas sebagai strategi komunikasi yang dilakukan dalam bahasa Jepang, dan (2) bagaimana kaitan penggunaan intensitas terhadap tujuan strategi komunikasinya. Metode yang digunakan dalam penelitian ini adalah deskriptif kualitatif, karena penganalisisan dilakukan secara pendeskripsian dari temuan data-data. Sumber data penelitian ini diambil dari drama Jepang Great Teacher Onizuka Remake karya Imai Kazuhisa, karena ditemukan banyak data mengenai penggunaan intensitas yang dianggap dapat mewakili cara tindak komunikasi masyarakat Jepang. Data dari penelitian ini diperoleh dari menyimak drama, dan mentranskripsikan dialog-dialog yang menggunakan intensitas, kemudian proses analisis dan membuat simpulan. Hasil penelitian adalah (1) penggunaan intensitas dalam tindak komunikasi bergantung dengan konteks emotif yang berlaku. Dalam penggunaan intensitas ditemukan seluruh konteks emotif yaitu, konteks kejutan, konteks takut, konteks marah, konteks sedih, konteks keinginan, konteks kebahagiaan, konteks kebosanan. Dari seluruh konteks emotif yang ada, penggunaan intensitas paling banyak muncul pada konteks kejutan, (2) penggunaan intensitas sangat berpengaruh dalam tujuan komunikasi yang diharapkan yaitu untuk memberitahu, memotivasi, mendidik, menyebarkan informasi, mendukung perbuatan keputusan. Dengan menggunakan intensitas lawan tutur berhasil mendapatkan apa yang diharapkan dari tindak komunikasi tersebut.
\end{abstract}

Kata kunci :konteks keinginan, konteks kebahagiaan, konteks kebosanan

Abstract: The Intensity or speech stress is often used by human being in communication unconsciously. The intensity is usually used to attract the partner in doing the communication. The speaker uses intensity in a hope that this will help his hearer to be more understanding of what is being delivered. Therefore, intensity in speech act is always attached to emotive context which surrounds the act of communication. The research is carried out in order to describe: (1) how is intensity emotive context used as a communicative strategy in Japanese, (2) how is the relation of the use of intensity toward the its goal of communication. Descriptive qualitative is employed to describe the data. The source of the data is taken from Japanese play Great Teacher Onizuka Remake by Imai Kazuhisa. There are many intensities found in the play which can be considered as the representation of they way Japanese people 
carry out communication act. The data are achieved by comprehending the play, transcribing the dialogues of the play which have intensities carefully, analyzing, and then concluding. The analysis denotes that (1) the use of intensities in communication act depends on emotive context. In making use of intensities, there are some emotive contexts; surprise context, fear context, angry context, sad context, want context, happy context, and get bored context. From those emotive contexts above, surprise context is mostly used by the speakers, (2) the use of intensity is influencing in getting the communicative goal; they are to let others know, to motivate, to teach, to give information, to support the decision. By using the intensity, the partner in doing the communication is successful in getting what he/she really needs in doing the act of communication.

Keywords: speech act, communication goal, want context, happiness context, get bored context

\section{Pendahuluan}

Bahasa digunakan dalam proses komunikasi manusia sehari-hari. Salah satu fungsi bahasa adalah sebagai media untuk menyampaikan ide, pikiran, hasrat dan keinginan kepada orang lain (Sutedi 2011: 2). Chaer menyatakan bahwa bahasa adalah sebuah sistem lambang, berupa bunyi, bersifat arbitrer, produktif dan manusiawi (1995: 14). Dengan adanya bahasa sebagai sistem lambang tersebut, bahasa digunakan alat komunikasi atau alat interaksi. Tetapi yang paling penting adalah ide, pikiran, hasrat, dan keinginan tersebut dituangkan melalui bahasa, maksudnya bahasa dapat membantu ketika menyampaikan ide, pikiran, hasrat, dan keinginan kepada seseorang baik secara lisan maupun tertulis. Lawan tutur dapat menangkap apa yang dimaksud karena lawan tutur memahami makna yang dituangkan melalui bahasa tersebut. Jadi, fungsi bahasa adalah sebagai media untuk menyampaikan suatu makna kepada seseorang secara lisan maupun tertulis.

Komunikasi sehari-hari tidak akan lepas dari bahasa. Sebagai alat komunikasi manusia, bahasa adalah suatu sistem yang bersifat sistematis. Sistematis maksudnya bahwa bahasa itu bukan suatu sistem tunggal, melainkan terdiri pula dari beberapa subsistem fonologi, subsistem morfologi, subsistem sintaksis dan subsistem semantik (Chaer 1995:4). Dari penjelasan ini, dapat dilihat bahwa dalam tindak komunikasi sehari-hari manusia tidak dapat lepas dari subsistem fonologis dalam ujaran untuk mengungkapkan gagasan yang akan disampaikan. Subsistem fonologis ini meliputi aksen, intonasi, nada, tekanan, jeda.

Level fonologi penting dalam tindak komunikasi, misalnya penggunaan penekanan pada kata yang salah dalam sebuah tuturan dapat membedakan maksud atau tujuan yang akan disampaikan.

Penekanan kata pada suatu ujaran ini disebut dengan 「インテンシティー」, selanjutnya ditulis intensitas. Dalam bahasa Jepang, misalnya ujaran "umai naaa" mengalami penekanan pada pengucapan "na". Ini digunakan untuk lebih memperkuat maksud yang akan disampaikan daripada hanya mengucapkan secara datar tetapi tidak mengubah makna dari ucapan "na" itu sendiri. Penekanan ujaran ini juga tidak terlepas dari konteks pada saat tindak komunikasi berlangsung. Hal ini sangat berkaitan karena memberi efek pada keberhasilan komunikasi antara penutur dengan lawan tutur. Penekanan Ujaran ini tidak sama dengan intonasi, 
karena menurut Isao (2001:28) intonasi adalah perubahan tinggi rendahnya bunyi yang diucapkan pada akhir kalimat yang dapat membedakan arti. Sedangkan intensitas seperti menurut Tokieda (1980) merupakan penekanan ujaran yang tidak mengubah makna inti kata, tetapi mengubah makna tuturan secara keseluruhan dan tidak hanya terpaku pada bagian akhir kalimat tuturan saja. Penekanan ujaran ini dilakukan untuk lebih menarik perhatian lawan tutur. Jadi dapat dilihat bahwa untuk mengetahui fungsi penggunaan intensitas yang dilakukan penutur terhadap lawan tutur, harus dilihat dari konteks yang melatarbelakangi tuturan tersebut berlangsung, sedangkan fungsi intonasi dapat langsung diketahui dari perubahan nada yang dilakukan penutur di akhir kalimat yang dituturkan.

Kemudian, Menurut Muslich (2011:114) penggunaan intensitas berhubungan dengan durasi, yang dalam tindak komunikasi tidak fungsional dalam kata, tetapi fungsional dalam tataran kalimat. Tetapi, Tokieda (1980) menyatakan bahwa intensitas merupakan sebuah penekanan dari sebuah kata dalam sebuah tindak komunikasi yang mengubah struktur kata tersebut tetapi tidak mengubah arti secara leksikalnya. Dari kedua pernyataan di atas dapat disimpulkan bahwa intensitas tidak mempengaruhi arti kata tersebut secara leksikal tapi mempengaruhi bentuk dan makna secara konteks.

Berikut adalah contoh tindak komunikasi dalam film Great Teacher Onizuka yang mengandung intensitas.

かんざき：あたし、死んじゃうかな。

(Kanzaki) : atashi, shinjau kana.

: "Lebih baik saya mati saja"

鬼塚：しんだら、なーーんもなくな ぞ。

(Onizuka) : shindara, naaan mo nakunaru zo.
: "kalau mati, apapun akan hilang lho"

Dari kalimat di atas, penggunaan tuturan naaan 「なーーん」 ditekankan lawan tutur untuk lebih menekankan maksud yang akan disampaikan. Bentuk kata naaantidak baku karena mengalami penekanan. Kata naaandalam tuturan di atas mengalami perubahan bentuk dari kata “nani”「なに」 mendapatkan penekanan dengan ucapan yang panjang dan perubahan bunyi di akhir menjadi naaan「なーー L」. Penekanan inilah yang dinamakan intensitas. Tokieda (1980) menambahkan bahwa penekanan pada bagian kata dalam sebuah tuturan yang diucapakan tidak mempengaruhi arti kata tersebut, tetapi dapat mempengaruhi reaksi lawan tutur terhadap penekanan tersebut. Oleh karena itu, pemilihan penutur dalam melakukan penekanan pada bagian kata tersebut dalam suatu tuturan juga tidak terlepas dari konteks yang terjadi pada saat tuturan berlangsung dan tujuan strategi komunikasi yang diharapkan penutur. Penelitian ini dilakukan dengan alasan karena penggunaan intensitas dalam berbahasa sering dilakukan penutur secara tidak disadari atau bahkan salah dalam melakukan penekanan dalam ujaran dalam suatu tindak komunikasi, padahal penggunaan ini penting untuk menyampaikan maksud dan ditujukan agar lebih mengenai perasaan lawan tutur. Oleh karena itu, Penelitian ini mendeskripsikan dan menjabarkan lebih luas tentang bentuk dan fungsi intensitas dalam tindak komunikasi bahasa Jepang sesuai dengan konteks yang terjadi, maksudnya menggabungkan antara proses fonologis yang muncul dalam sebuah tindak komunikasi dengan fungsi kontekstual yang ada dan dikaitkan dengan tujuan dari strategi komunikasi.

Jakobson (1998:123) membagi fungsi ujaran menjadi beberapa bagian yang 
di dalamnya terdapat fungsi emotif. Dalam penelitian ini konteks akan dikaitkan dengan fungsi emotif, yang kemudian dihubungkan dengan tujuh fungsi konteks emotif menurut Boeree (2008:124) yaitu kejutan, takut, marah, sedih, keinginan, kebahagiaan, kebosanan. Kemudian tujuan strategi komunikasi menurut Liliweri (2011:248-250) yaitu untuk memberitahu, memotivasi, mendidik, menyebarkan informasi, mendukung perbuatan keputusan.

Data tindak komunikasi bahasa Jepang dalam penelitian ini didapat dari drama Great Teacher Onizuka Remake karya Imai Kazuhisa. Drama ini menjadi drama yang memiliki rating tertinggi dan palin disukai waraga Jepang pada tahun 2012. Drama ini menceritakan tentang kisah seorang tukang kebun bernama Onizuka Eikichi yang akhirnya diangkat menjadi seorang guru di SMA Meishu Gakuen. Onizuka diberi tangggung jawab menjadi wali kelas dari kelas 2-4 yang terkenal dengan anak-anaknya yang nakal. Di sinilah kisah peran Onizuka dimulai. Dengan gayanya yang santai dan urakan Onizuka berusaha menyatukan kelas 2-4 yang bermasalah itu. Dalam drama 13 episode yang diproduksi oleh Fuji TV pada tahun 2012 ini banyak ditemukan penggunaan intensitas dalam tuturan para pemerannya, terutama Onizuka sebagai seorang guru yang juga menggunakan strategi dalam berkomunikasi dengan murid-muridnya dalam usahanya menyatukan muridmuridnya yang nakal. Pemilihan penekanan ujaran dalam suatu tuturan ini menarik untuk dikaji karena saling berhubungan dengan konteks dan tujuan strategi komunikasi yang diharapkan.

Dengan penelitian ini diharapkan dapat menjadi dasar yang dapat digunakan untuk mengetahui cara orang Jepang dalam berkomunikasi, terutama bagian-bagian yang biasa orang Jepang tekankan dalam suatu tuturan untuk menarik perhatian lawan tutur.

\section{Metode Penelitian}

Metode yang digunakan dalam penelitian ini adalah analisis deskriptif kualitatif karena metode ini dianggap sesuai dan dapat menjawab permasalahan. Metode analisis digunakan dalam penelitian ini untuk membantu menguraikan dan menganalisis data-data tentang bagaimana hubungan bentuk dan fungsi kontekstual penggunaan intensitas dengan tujuan dari strategi komunikasi, seperti menganalisis fungsi penggunaan sesuai dengan fungsi konteks emotifnya dan dikaitkan dengan tujuan dari strategi komunikasi tindak komunikasi bahasa Jepang dalam drama Great Teacher Onizuka Remake,kemudian metode deskriptif digunakan untuk membantu menjelaskan, mendeskripsikan dan membuat gambaran secara sistematis bantuk dan fungsi kontekstual dari penggunaan intensitas dalam tindak komunikasi bahasa Jepang sesuai dengan konteks emotifnya dan hubungannya dengan tujuan strategi komunikasi, lalu mendeskripsikan hasil analisis sesuai dengan rumusan masalah dalam penelitian ini. Metode penelitian deskriptif cenderung digunakan dalam penelitian kualitatif terutama dalam mengumpulkan data, serta menggambarkan data secara alamiah. Data dari penelitian ini adalah tuturan tindak komunikasi bahasa Jepang yang menggunakan intensitas.

Penelitian ini juga menggunakan teknik telaah pustaka karena pemecahan masalah mengenai bentuk dan fungsi penggunaan intensitas dan hubungannya dengan tujuan strategi komunikasi ini ditinjau berdasarkan bahan-bahan pustaka yang relevan. Bahan pustaka yang digunakan dalam penelitian ini adalah artikel hasil penelitian dalam jurnal ilmiah, buku, video, film, dan wacana yang berisi tentang referensi sesuai apa yang dikaji dalam penelitian ini.

Pengumpulan data dilakukan
dengan


mengidentifikasi dan menemukan film atau drama yang menggunakan intensitas. Metode yang digunakan dalam mengobservasi film atau drama ini adalah metode simak, sesuai dengan pendapat Mahsun (2005:90) yang menyatakan bahwa metode simak adalah metode yang digunakan untuk memperoleh data yang dilakukan dengan menyimak penggunaan bahasa. Metode simak digunakan karena data tuturan pertanyaan ini didapat dengan cara menyimak dialog yang dilakukan oleh para tokoh dalam film atau drama tersebut.

Langkah-langkah yang dilakukan dalam pengumpulan data adalah sebagai berikut:

1. Menyimak drama Great Teacher Onizuka Remake yang memiliki penggunaan intensitas, kemudian mentranskripsikannya ke dalam teks.

2. Mengumpulkan data berupa tuturan yang menggunakan intensitas yang terdapat dalam drama Great Teacher Onizuka Remake .

3. Mencatat data tuturan yang menggunakan intensitas dalam tindak komunikasi bahasa Jepang yang berbeda-beda yang terdapat dalam drama Great Teacher Onizuka Remake.
4. Memberi penomeran pada data. Memberikan nomor setiap kata atau bagian data yang menggunakan intensitas pada drama Great Teacher Onizuka Remake untuk memudahkan mengklasifikasi berdasarkan rumusan masalah. Misalnya dengan pemberian kode (GTOR/1/12.25), kode ini digunakan untuk mempermudah analisis. Kode GTOR adalah data yang terdapat dalam drama Great Teacher Onizuka Remake, nomor 1 berarti data terletak pada episode 1, dan 12.25 menandakan berarti data terletak pada menit ke 12.25.

5. Mengklasifikasikan data yang menggunakan intensitas dalam tindak komunikasi bahasa Jepang dalam drama Great Teacher Onizuka Remake yang disesuaikan dengan tujuan penelitian.

\section{Hasil Penelitian dan Pembahasan}

\section{Hasil Penelitian}

Berikut ini disajikan hasil temuan data tentang Intensitas dalam konteks emotif dan kaitannya dengan tujuan strategi komunikasi yang diperoleh dari drama Great Teacher Onizuka Remake karya Imai Kazuhisa. 
Tabel 3.1

Klasifikasi Data Kaitan Konteks Emotif dengan Tujuan Strategi Komunikasi

\begin{tabular}{|c|c|c|c|c|c|c|c|c|c|}
\hline \multirow[t]{2}{*}{ No. } & \multirow[t]{2}{*}{$\begin{array}{l}\text { konteks } \\
\text { emotif }\end{array}$} & \multirow[t]{2}{*}{$\begin{array}{c}\text { Jumlah } \\
\text { data }\end{array}$} & \multirow[t]{2}{*}{ Kode data } & \multicolumn{5}{|c|}{$\begin{array}{l}\text { Tujuan Strategi } \\
\text { Komunikasi }\end{array}$} & \multirow[t]{2}{*}{$\begin{array}{l}\text { Data } \\
\text { Tuturan }\end{array}$} \\
\hline & & & & A & $\mathrm{B}$ & $\mathrm{C}$ & $\mathrm{D}$ & $\mathrm{E}$ & \\
\hline 1 & $\begin{array}{l}\text { Konteks } \\
\text { kejutan }\end{array}$ & $\begin{array}{c}15 \\
\text { Data }\end{array}$ & $\begin{array}{l}\text { GTOR } \\
/ 2 / 16.64\end{array}$ & & & & & $\mathrm{X}$ & $\begin{array}{l}\text { ひゃーっくまん } \\
\text { 円?. }\end{array}$ \\
\hline 2 & $\begin{array}{c}\text { Konteks } \\
\text { takut }\end{array}$ & 7 data & $\begin{array}{l}\text { GTOR } \\
/ 4 / 17.00\end{array}$ & $\mathrm{X}$ & & & & & 藤吉。すまん！ \\
\hline 3 & $\begin{array}{c}\text { Konteks } \\
\text { marah }\end{array}$ & 13 data & $\begin{array}{l}\text { GTOR/2/ } \\
05.11\end{array}$ & & & & $\mathrm{X}$ & & $\begin{array}{l}\text { 女子生徒を暴 } \\
\text { 行! }\end{array}$ \\
\hline 4 & $\begin{array}{l}\text { Konteks } \\
\text { sedih }\end{array}$ & 2 data & $\begin{array}{l}\text { GTOR } \\
/ 6 / 34.31\end{array}$ & & $X$ & & & & $\begin{array}{l}\text { 嫌になることば } \\
\text { っか }\end{array}$ \\
\hline 5 & $\begin{array}{c}\text { Konteks } \\
\text { keingina } \\
\mathrm{n}\end{array}$ & 12 data & $\begin{array}{r}\text { GTOR } \\
/ 2 / 30.27\end{array}$ & $\mathrm{X}$ & & & & & $\begin{array}{l}\text { 嫌だなあ〜って } \\
\text { 思って。 }\end{array}$ \\
\hline 6 & $\begin{array}{c}\text { Konteks } \\
\text { kebahagi } \\
\text { aan }\end{array}$ & 4 data & $\begin{array}{l}\text { GTOR } \\
/ 4 / 24.15\end{array}$ & $\bar{X}$ & & & & & うんめえ〜! \\
\hline 7 & $\begin{array}{c}\text { Konteks } \\
\text { kebosana } \\
\mathrm{n}\end{array}$ & 2 data & $\begin{array}{l}\text { GTOR } \\
/ 7 / 18.36\end{array}$ & & & $\mathrm{X}$ & & & $\begin{array}{l}\text { な〜んも } ＼mathrm{~ な く ~} \\
\text { なるぞ。 }\end{array}$ \\
\hline
\end{tabular}

Ket:

Tujuan strategi komunikasi:
A. Memberitahu (announcing)
B. Memotivasi (Motivating)
C. Mendidik (Educating)
D. Menyebarkan informasi (Informing)
E. Mendukung perbuatan keputusan (Supporting Decision Making)

Berdasarkan tabel di atas, dapat dilihat hasil yang sangat bervariatif mengenai keterkaitan penggunaan intensitas dalam fungsi konteks emotif dan tujuan strategi komunikasinya. Jika dilihat dari data tabel di atas, tujuan penggunaan intensitas dalam tindak komunikasi bisa jadi sama, tapi intensitas atau penekanan itu memiliki konteks emotif yang bisa saja berbeda. Untuk lebih jelasnya, berikut disajikan analisis keterkaitan penggunaan intensitas dengan fungsi konteks emotif dan tujuan strategi komunikasi yang digunakan berikut ini. Data yang analisis adalah data yang dianggap representatif sesuai dengan tujuan penelitian.

\section{Pembahasan}

Berikut analisis pembahasan hasil temuan data yang diperoleh dari drama Great Teacher Onizuka Remake karya Imai Kazuhisa. Pembahasan diambil dari data yang dianggap representatif dan sesuai untuk menjawab permasalahan. 


\section{a. Penggunaan Intensitas dalam konteks kejutan dengan tujuan mendukung perbuatan keputusan}

Berikut akan disajikan analisis keterkaitan penggunaan intensitas dikaitkan dengan konteks emotif kejutan dan tujuan penggunaan intensitas untuk mendukung perbuatan keputusan.

Konteks : Katsuragi yang jengkel pada Onizuka memanggil Onizuka ke Taman dan membayar orang dan sekumpulan geng untuk memukul Onizuka. Onizuka datang ke taman dan kaget atas tingkah laku Katsuragi.

(1)

$$
\begin{aligned}
\text { Onizuka } & : \text { どちら様? } \\
& : \text { dochira sama? } \\
& : \text { "siapa mereka?” }
\end{aligned}
$$

Katsuragi： 私が闇サイトで集めたのよ。 あんたを倒したら 100 万 円あげるってね。

: watashi ga saito de atsumeta no yo. Anta wo taoshitara shoukin 100 man en ageru tte ne.

: "Aku mengumpulkan mereka dari internet. aku mengatakan kalau bisa menjatuhkan kamu aku akan beri upah 1 juta yen."

Onizuka : ひゃーっくまん円?

: hyaaakku man en?

:"1 juta yen?"

Katsuragi：そう。どんどん集まるわよ。

: Sou. dondon atsumaru wa yo

: "Ya, makanya semakin banyak yang berkumpul."

(GTOR /2/16.64)

Dari tuturan (1), tuturan Onizuka hyaakku man 「ひゃーっくまん」 memiliki penekanan bunyi gabungan bunyi panjang dengan penggunaan sokuon. Bagian itu dipilih oleh Onizuka untuk lebih ditekankan daripada bagian yang lain karena kata hyaakku man yang menjadi inti dari seluruh tindak komunikasi yang dilakukan. Ini terkait dengan konteks, di mana Onizuka terkejut dengan tindakan Katsuragi yang berani membayar satu juta yen hanya untuk menghabisi Onizuka. Bagianhyaakku man menjadi bagian penting dalam konteks kejutan dalam tindak komunikasi ini. Dengan menyampaikan ini, Onizuka merasa ia telah menarik perhatian lawan tutur, terlihat dari reaksi senang yang diperlihatkan Katsuragi saat melihat Onizuka terkejut. Katsuragi membayar orang banyak untuk menghabisi Onizuka yang dianggap telah mengganggunya.

Dalam konteks ini, Onizuka menekankan ucapannya dengan hyaakku man agar lebih menarik perhatian lawan tutur. Tetapi dalam konteks kali ini, penekanan yang diucapkan Onizuka kontra dengan teori yang ada mengenai tujuan komunikasi yang akan disampaikan. Jika saja diucapkan secara datar, kemungkinan Katsuragi menilai bahwa Onizuka tidak masalah atau dengan kata lain setuju dengan tindakan Katsuragi. Tapi dengan penggunaan intensitas pada hyaakku man, Onizuka menunjukkan ketidasetujuannya dengan apa yang telah dilakukan Katsuragi. Ini kontra dengan teori tujuan komunikasi tentang mendukung keputusan.

Berdasarkan penjabaran di atas terlihat bahwa kaitan erat antara strategi komunikasi dengan penggunaan intensitas yaitu dengan menekankan salah satu bagian dalam tuturan yang diucapkan dan hubungannya dengan konteks emotif yang ada pada saat tindak komunikasi berlangsung akan mempengaruhi tujuan dari komunikasi yang dilakukan. Tetapi, untuk tindak komunikasi di atas ini, hubungan strategi penggunaan intensitas dalam tindak komunikasi ini berhubungan, tetapi memiliki hubungan yang kontra dengan teori karena tidak mempunyai pengaruh akan hasil yang akan dicapai yaitu mendukung perbuatan keputusan. 


\section{b. Penggunaan Intensitas dalam konteks takut dengan tujuan memberitahu}

Berikut akan disajikan analisis keterkaitan penggunaan intensitas atau penekanan pada akhir tuturan, dikaitkan dengan konteks emotif takut dan tujuan penggunaan intensitas untuk memberitahu.

Konteks : Onizuka merasa bersalah, karena telah menggunakan uang kas kelas 2-4 untuk pergi minumminum di bar, yang ia pikir uang itu adalah gaji pertamanya sebagai guru.

(2)

$$
\begin{aligned}
\text { Onizuka } & : \text { 藤吉。すまん! } \\
& : \text { Fujiyoshi, Suman! } \\
& : \text { "Fujiyoshi, maaf!”’ } \\
\text { Murai } & : \text { おい, どういうことだよ。 } \\
& : \text { oi, dou iu koto ka. } \\
& : \text { “hei, apa maksudnya ini?” } \\
\text { Onizuka } & : \text { 林間学校の金使ったの, どう } \\
& \text { やら俺らしい。 } \\
& : \text { rinkangakkou no okane tsukatta } \\
& \text { no, douyara bokurashii. } \\
& : \text { “Uang iuran sekolah, sepertinya } \\
& \text { aku yang pakai” }
\end{aligned}
$$

$(\mathrm{GTOR} / 4 / 17.00)$

Dari tuturan (2), bunyi tuturan Onizuka suman「すまん」 memiliki penekanan pada akhir ucapannya. Bagian itu dipilih oleh Onizuka untuk lebih ditekankan daripada bagian yang lain karena kata suman yang menjadi inti dari seluruh tindak komunikasi yang dilakukan oleh Onizuka. Ini terkait dengan konteks, di mana keadaan saat itu memang Onizuka bersalah karena telah menggunakan uang kas kelas untuk berfoya-foya dengan temannya, Saejima. Onizuka pikir itu adalah uang gaji pertamanya. Dari keadaan inilah terlihat konteks emotif takut Onizuka, sehingga ia menekankan pada kata suman sebagai tanda minta maaf ia pada Fujiyoshi, yang sebenarnya memiliki tanggung jawab menyimpan uang tersebut. Dengan menyampaikan ini Onizuka merasa mengurangi beban rasa takutnya.

Kemudian, dalam konteks takut ini Onizuka menggunakan strategi dalam komunikasinya dengan Fujiyoshi. Strategi komunikasi yang dilakukan Onizuka dengan menekankan ucapannya pada bagian suman agar lebih menarik perhatian Fujiyoshi dan lebih mengena daripada hanya diucapkan secara datar. Jika saja diucapkan secara datar, kemungkinan Fujiyoshi akan sangat marah padanya. Tetapi kenyataannya Fujiyoshi memaafkan Onizuka. Strategi komunikasi dengan menekankan pada satu bagian kata ini dilakukan Onizuka dengan tujuan untuk memberitahu keadaan yang sebenarnya. Tujuan memberitahu ini berhasil tercapai, sehingga mengurangi beban Fujiyoshi yang bingung atas kehilangan uang itu.

Berdasarkan penjabaran di atas tertlihat bahwa kaitan erat antara strategi komunikasi dengan penggunaan intensitas yaitu dengan menekankan salah satu bagian dalam tuturan yang diucapkan dan hubungannya dengan konteks emotif yang ada pada saat tindak komunikasi berlangsung akan mempengaruhi tujuan dari komunikasi yang dilakukan. Strategi penggunaan intensitas dalam tindak komunikasi ini berhasil karena tujuan dari strategi komunikasinya untuk memberitahu telah tersampaikan.

\section{c. Penggunaan Intensitas dalam konteks marah dengan tujuanmenyebarkan informasi}

Berikut akan disajikan analisis keterkaitan penggunaan intensitas atau penekanan pada sokuon, dikaitkan dengan konteks emotif marah dan tujuan penggunaan intensitas untuk menyebarkan informasi.

Konteks : Uchiyamada sensei sebagai wakil kepala sekolah marah dengan pemberitaan terkait dengan 
(3)

Onizuka sensei yang bertindak tidak sopan pada siswi, dan akhirnya menimbulkan masalah. Kemudian, Uchiyamada sensei menyampaikan berita itu ke yayasan sekolah. Kejadiannya di ruang yayasan.

Uchiyamada: 理事長お聞きになりまし たか?教師がじょっし生 徒を暴行!

: Rijichou

okikininarimashitaka?

kyoushi ga josshiseito wo boukou!

: "Ketua yayasan, apa sudah dengar? guru menyerang murid perempuannya"

Yamatama : 未遂です。

: misui desu.

: "berusaha menyerang."

Uchiyamada: 同じだ。これは非常事態 です。我が明修学苑始ま って以来の不祥事です!

Onaji da. Kore wa hijoujitai desu. wa ga meishuu gaku sono hajimatte irai no fushouji!

: "sama saja. ini keadaan darurat. ini permulaan skandal yang akan terjadi di sekolah kita"

(GTOR/2/ 05.11)

Dari tuturan (3), tuturan Uchiyamada senseijosshi「じょっし」 memiliki penekanan bunyi konsonan rangkap (sokuon). Bagian itu dipilih oleh Uchiyamada sensei untuk lebih ditekankan daripada bagian yang lain karena kata josshiyang menjadi inti dari seluruh tindak komunikasi yang dilakukan. Ini terkait dengan konteks, di mana keadaan saat itu, Uchiyamada sensei marah setelah mengetahui Onizuka ditahan polisi karena bertindak tidak sopan terhadap seorang siswi. Bagian josshi menjadi bagian penting dalam konteks kemarahan dalam tindak komunikasi ini. Dengan menyampaikan ini, Uchiyamada sensei merasa ia telah menarik perhatian lawan tutur dalam hal ini ketua yayasan, terlihat dari reaksi ketua yayasan yang menyimak reaksi marah dari Uchiyamada sensei.

Dalam konteks ini, Uchiyamada sensei menekankan ucapannya pada bagian josshi agar lebih menarik perhatian ketua yayasan dan lebih mengena daripada hanya diucapkan secara datar. Jika saja diucapkan secara datar, kemungkinan pesan marah yang disampaikan kepada ketua yayasan tidak akan tercapai. dan ketua yayasan akan menganggap Uchiyamada sensei tidak masalah dengan hal yang berhubungan dengan Onizuka tersebut. Tetapi dengan strategi menekankan pada bagian itu, Uchiyamada sensei merasa bahwa tujuannya untuk memberi informasi pada ketua yayasan, telah tersampaikan. Strategi komunikasi dengan menekankan pada satu bagian kata yang dilakukan Uchiyamada sensei ini berhasil tercapai.

Berdasarkan penjabaran di atas terlihat bahwa kaitan erat antara strategi komunikasi dengan penggunaan intensitas yaitu dengan menekankan salah satu bagian dalam tuturan yang diucapkan dan hubungannya dengan konteks emotif yang ada pada saat tindak komunikasi berlangsung akan mempengaruhi tujuan dari komunikasi yang dilakukan. Strategi penggunaan intensitas dalam tindak komunikasi ini berhasil karena tujuan dari strategi komunikasinya untuk memberi informasi telah tersampaikan.

\section{d. Penggunaan Intensitas dalam konteks marah dengan tujuan memotivasi}

Berikut akan disajikan analisis keterkaitan penggunaan intensitas atau penekanan pada sokuon, dikaitkan dengan konteks emotif marah dan tujuan 
penggunaan intensitas untuk mendukung perbuatan keputusan.

Konteks : Fuyutsuki sensei merasa bersalah dan sedih pada muridnya Kujirakawa. Kemudian Fuyutsuki sensei datang pada Kujirakwa untuk meminta maaf, sekaligus memberi motivasi tentang masalah yang ada pada Kujirakawa dengan membandingkannya dengan masalah yang ada pada dirinya.

Fuyutsuki : すごいコンプレックス。ほ んとだめだめで自分でも嫌 になることばっか。でもね …でも...これが私なの。

:sugoi kompureksu. Honto damedame de jibun demo kirai ni naru koto bakka. demo ne, demo, kore ga watashi na no.

: "sangat kompleks. benar-benar buruk, sensei terus membenci diri sendiri."

Miho

$$
\begin{aligned}
& \text { : なに?あれ。 } \\
& \text { : nani? are. } \\
& \text { : “Apa itu.” }
\end{aligned}
$$

(GTOR /6/34.31)

Dari tuturan (4), tuturan Fuyutsuki sensei bakka「ばっか」 memiliki penekanan bunyi konsonan rangkap (sokuon). Bagian itu dipilih oleh Fuyutsuki sensei untuk lebih ditekankan daripada bagian yang lain karena kata bakkayang menjadi inti dari seluruh tindak komunikasi yang dilakukan. Ini terkait dengan konteks, di mana keadaan saat itu, Fuyutsuki sensei sedih telah menyakiti perasaan Kujirakawa. Bagianbakka menjadi bagian penting dalam konteks kesedihan dalam tindak komunikasi ini. Dengan menyampaikan ini, Fuyutsuki sensei merasa ia telah menarik perhatian lawan tutur, terlihat dari reaksi Kujirakawa yang terlihat berkaca-kaca setelah
Fuyutsuki sensei mengucapkan itu. Tuturan bakka ini bukan berarti umpatan, tapi berasal dari kata bakkari「ばっかり」 yang mengalami penyingkatan ucapan.

Dalam konteks ini, Fuyutsuki sensei menekankan ucapannya dengan umpatan bakka agar lebih menarik perhatian Onizuka dan lebih mengena daripada hanya diucapkan secara datar. Jika saja diucapkan secara datar, kemungkinan pesan marah yang disampaikan Fuyutsuki sensei kepada Kujirakawa tidak akan memiliki pengaruh yang signifikan. Tetapi dengan strategi menekankan pada bagian itu, Fuyutsuki sensei merasa bahwa tujuannya untuk memotivasi Kujirakawa, telah tersampaikan. Motivasi ini diberikan pada Kujirakawa agar ia tidak lagi merasa rendah diri akan keadaan fisiknya. Strategi komunikasi dengan menekankan pada satu bagian kata yang dilakukan Fuyutsuki sensei ini berhasil tercapai, terbukti dari respon Kujirakawa yang akhirnya berterima kasih pada Fuyutsuki sensei.

Berdasarkan penjabaran di atas terlihat bahwa kaitan erat antara strategi komunikasi dengan penggunaan intensitas yaitu dengan menekankan salah satu bagian dalam tuturan yang diucapkan dan hubungannya dengan konteks emotif yang ada pada saat tindak komunikasi berlangsung akan mempengaruhi tujuan dari komunikasi yang dilakukan. Strategi penggunaan intensitas dalam tindak komunikasi ini berhasil karena tujuan dari strategi komunikasinya untuk memotivasi telah tersampaikan.

\section{e. Penggunaan Intensitas dalam konteks keinginan dengan tujuan memberitahu}

Berikut akan disajikan analisis keterkaitan penggunaan intensitas atau penekanan pada ucapan panjang choon, dikaitkan dengan konteks emotif keinginan 
dan tujuan penggunaan intensitas untuk memberitahu.

Konteks: Miyabi yang tidak senang dengan

Onizuka sensei tidak senang melihat reaksi dari Kanzaki. Kemudian Miyabi menanyakan mengapa Kanzaki bereaksi seperti itu. Kanzaki menjawab dengan tenang bahwa ia tidak ingin kejadian yang pernah terjadi pada kelas 2-4 terjadi kembali.

(5)

$$
\begin{aligned}
\text { Miyabi } & \text { : なにが言いたいの? } \\
& \text { : nani ga iitai no? } \\
& \text { :apa yang ingin kamu katakan? }
\end{aligned}
$$

Kanzak : また、あんな悲劇が起きたら

嫌だなあ〜って思って。

: Mata, anna higeki ga okitara iya danaatteomotte.

: aku tidak mau tragedi itu terjadi lagi.

(GTOR /2/30.27)

Dari tuturan (5), tuturan Kanzakiiya da naaa 「嫌だなあ〜」 memiliki penekanan bunyi panjang (choon). Bagian itu dipilih oleh Kanzaki untuk lebih ditekankan daripada bagian yang lain karena kata iya da naaa yang menjadi inti dari seluruh tindak komunikasi yang dilakukan oleh Kanzaki. Ini terkait dengan konteks, di mana keadaan saat itu, Kanzaki ingin menyampaikan pada Miyabi bahwa ia tidak ingin kejadian yang pernah terjadi di kelas mereka dulu, terjadi lagi saat ini. Kanzaki merasa perlu menyampaikan hal itu pada Miyabi karena melihat Miyabi yang bertindak berani melawan Onizuka yang merupakan wali kelasnya. Bagian iya da naaa menjadi bagian penting dalam konteks keinginan dalam tindak komunikasi antara Kanzaki dan Miyabi ini. Dengan menyampaikan ini Kanzaki merasa ia telah menarik perhatian lawan tutur, terlihat dari reaksi tidak senang dari Miyabi. Reaksi
Miyabi menunjukkan sikap negatifnya terhadap ucapan Kanzaki.

Dalam konteks ini, Kanzaki menekankan ucapannya pada bagian iya $d a$ naaa agar lebih menarik perhatian Miyabi dan lebih mengena daripada hanya diucapkan secara datar. Jika saja diucapkan secara datar, kemungkinan Miyabi tidak akan mempedulikan Kanzaki. Tetapi dengan strategi menekankan pada bagian itu, Kanzaki merasa bahwa tujuannya untuk memberitahu Miyabi tersampaikan, walaupun Miyabi menunjukkan reaksi tidak senang terhadap perkataan Kanzaki. Strategi komunikasi dengan menekankan pada satu bagian kata yang dilakukan Kanzaki ini berhasil tercapai.

Berdasarkan penjabaran di atas terlihat bahwa kaitan erat antara strategi komunikasi dengan penggunaan intensitas yaitu dengan menekankan salah satu bagian dalam tuturan yang diucapkan dan hubungannya dengan konteks emotif yang ada pada saat tindak komunikasi berlangsung akan mempengaruhi tujuan dari komunikasi yang dilakukan. Strategi penggunaan intensitas dalam tindak komunikasi ini berhasil karena tujuan dari strategi komunikasinya untuk memberitahu telah tersampaikan.

\section{f. Penggunaan Intensitas dalam konteks kebahagiaan dengan tujuan Memberitahu}

Berikut akan disajikan analisis keterkaitan penggunaan intensitas atau penekanan gabungan, dikaitkan dengan konteks emotif kebahagian dan tujuan penggunaan intensitas untuk memberitahu.

Konteks : Onizuka meminta menukar menu makan siangnya dengan menu makan siang Fujiyoshi yang dimasaknya sendiri. Fujiyoshi pun kaget dengan hal tersbut. Tetapi akhirnya Onizuka memakan masakan yang dibuat Fujiyoshi untuk makan siang 
tersebut dan memuji Fujiyoshi karena masakannya enak.

(6)

$$
\begin{aligned}
\text { Fujiyoshi } & \text { えっ,ちょっと俺の。 } \\
& : \text { e, chotto, ore no. } \\
& : \text { “eh, punyaku.” } \\
\text { Onizuka } & : \text { ロールキャベツじやねえか。 } \\
& \text { ああ? } \\
& \text { うんめえ〜!なにだ?これ。 } \\
& : \text { roorukyabetsu janeeka. a? } \\
& \text { Unmeee! nanda? kore. } \\
& \text { “ini rol cabbage kan? } \\
& \text { Wah enaaak! apa ini.” }
\end{aligned}
$$

(GTOR /4/24.15)

Dari tuturan (6), tuturan Onizuka unmeee 「うんめえ〜」 memiliki penekanan bunyi panjang (choon). Bagian itu dipilih oleh Onizuka untuk lebih ditekankan daripada bagian yang lain karena kata unmeee yang menjadi inti dari seluruh tindak komunikasi yang dilakukan oleh Onizuka. Ini terkait dengan konteks, di mana keadaan saat itu, Onizuka mencoba masakan Fujiyoshi, dan setelah mencobanya, Onizuka terkesan dengan rasanya. Onizuka merasa senang karena ternyata Fujiyoshi memiliki bakat untuk memasak. Sehingga Onizuka tahu akan mengarahkan ke mana setelah Fujiyoshi lulus nanti. Bagianunmeee menjadi bagian penting dalam konteks senang Onizuka. Dengan menyampaikan ini Onizuka merasa ia telah menarik perhatian lawan tutur, terbukti dengan reaksi Fujiyoshi yang senang dipuji masakannya enak.

Dalam konteks kebahagiaan ini, Onizuka menekankan ucapannya pada bagian unmeee agar lebih menarik perhatian Fujiyoshi dan lebih mengena daripada hanya diucapkan secara datar. Jika saja diucapkan secara datar, kemungkinan Fujiyoshi hanya akan menganggap ucapan Onizuka tidak serius. Tetapi dengan strategi menekankan pada bagian itu, Onizuka merasa bahwa tujuannya untuk memberitahu Fujiyoshi tersampaikan. Strategi komunikasi dengan menekankan pada satu bagian kata ini dilakukan Onizuka dengan tujuan untuk memberitahu keadaan yang sebenarnya. Tujuan memberitahu ini berhasil tercapai oleh Onizuka, terlihat dari reaksi senang Fujiyoshi.

Berdasarkan penjabaran di atas terlihat bahwa kaitan erat antara strategi komunikasi dengan penggunaan intensitas yaitu dengan menekankan salah satu bagian dalam tuturan yang diucapkan dan hubungannya dengan konteks emotif yang ada pada saat tindak komunikasi berlangsung akan mempengaruhi tujuan dari komunikasi yang dilakukan. Strategi penggunaan intensitas dalam tindak komunikasi ini berhasil karena tujuan dari strategi komunikasinya untuk memberitahu telah tersampaikan.

\section{g. Penggunaan Intensitas dalam konteks keinginan dengan tujuan mendidik}

Berikut akan disajikan analisis keterkaitan penggunaan intensitas atau penekanan pada choon, dikaitkan dengan konteks emotif keinginan dan tujuan penggunaan intensitas untuk mendidik.

Konteks : Kanzaki yang merasa sedih karena ia merupakan anak yang berbeda dengan teman-temannya yang lain karena terlalu jenius, merasa kejeniusannya hanya dimanfaatkan untuk membantu perkejaan ibu nya saja. Dia merasa hidup yang bosan.

(7)

$$
\begin{aligned}
\text { Kanzaki } & : \text { 死んじやおっかな。 } \\
& : \text { Shinjaokkana } \\
& : \text { “Aku mati saja.” } \\
\text { Onizuka } & : \text { 死んだらな〜んもなくなる } \\
& \text { ぞ。 } \\
& : \text { Shindara naaan mo nakunaru }
\end{aligned}
$$


$z O$.

: "Kalau mati semua akan hilang loh."

$(\mathrm{GTOR} / 7 / 18.36)$

Dari tuturan (7), tuturan Onizukanaaan 「な〜ん」 memiliki penekanan bunyi panjang (choon). Bagian itu dipilih oleh Onizuka untuk lebih ditekankan daripada bagian yang lain karena kata naaanyang menjadi inti dari seluruh tindak komunikasi yang dilakukan. Ini terkait dengan konteks, di mana keadaan saat itu, Onizuka ingin menyampaikan pada Kanzaki agar tidak terlalu larut dalam kesedihaan, bahkan hingga membicarakan tentang kematian. Bagiannaaan menjadi bagian penting dalam konteks kesedihan dalam tindak komunikasi antara Onizuka dan Kanzaki ini. Dengan menyampaikan ini Onizuka merasa ia telah menarik perhatian lawan tutur, terlihat dari reaksi Kanzaki yang mendengarkan dengan baik perkataan Onizuka. Dan akhirnya Kanzaki menjadi ceria dan bersemangat setelah diberi nasihat oleh Onizuka

Dalam konteks ini, Onizuka menekankan ucapannya pada bagian naaan agar lebih menarik perhatian Kanzaki dan lebih mengena daripada hanya diucapkan secara datar. Jika saja diucapkan secara datar, kemungkinan Kanzaki akan menganggap Onizuka sama seperti yang lainnya, dan tidak dapat memecahkan masalahnya. Tetapi dengan strategi menekankan pada bagian itu, Onizuka merasa bahwa tujuannya untuk menasihati, mendidik Kanzaki tersampaikan. Strategi komunikasi dengan menekankan pada satu bagian kata yang dilakukan Onizuka ini berhasil tercapai.

Berdasarkan penjabaran di atas terlihat bahwa kaitan erat antara strategi komunikasi dengan penggunaan intensitas yaitu dengan menekankan salah satu bagian dalam tuturan yang diucapkan dan hubungannya dengan konteks emotif yang ada pada saat tindak komunikasi berlangsung akan mempengaruhi tujuan dari komunikasi yang dilakukan. Strategi penggunaan intensitas dalam tindak komunikasi ini berhasil karena tujuan dari strategi komunikasinya untuk mendidik telah tersampaikan.

\section{Penutup}

Berdasarkan pembahasan dan diskusi pada bab sebelumnya maka dapat disimpulkan menjadi beberapa hal berikut ini. Strategi penggunaan intensitas sangat berpengaruh pada konteks emotif pada saat terjadinya tindak komunikasi. Strategi penggunaan intensitas dengan konteks emotif kejutan adalah yang paling banyak dalam tindak komunikasi. Ini kemungkinan disebabkan karena data yang diambil merupakan drama, yang lebih mengharapkan respon kejutan dari penonton agar drama lebih terlihat menarik. Bagian yang ditekankan dalam sebuah tuturan dalam tindak komunikasi dapat mempengaruhi hasil dan tujuan komunikasi yang diharapkan. Strategi penggunaan intensitas dengan tujuan komunikasi untuk memberitahu paling banyak dalam tindak komunikasi. Penggunaan intensitas dapat digunakan untuk tujuan komunikasi yang bertentangan, misalnya ketidaksetujuan atau tidak mendukung suatu perbuatan keputusan. Seluruh analisis berdasarkan pada sumber data yang terdapat pada Drama Great Teacher Onizuka. Untuk sumber data yang lain, kemungkinan besar memiliki hasil yang berbeda.

\section{Daftar Pustaka}

Boeree. C. George. 2008. General Psychology. Yogyakarta: Prismasophie.

Faerch, Clause dan Kasper, Gabriele. 1983. Strategies in Interlanguage 
Communication. New York: Liliweri, Alo. 2011. Komunikasi Serba Ada Longman. Serba Makna. Jakarta: Prenada

Iori, Isao. 2001. Atarashii Nihongo Media Group.

gengogaku Nyuumon. Tokyo: Surie Network.

Iori, Isao. 2001. Chuukyuu wo Oshieru Hito no Tame no Nihongo Bunpou Handbook. Tokyo: 3A Network.

Jakobson, Roman. 1998. The Speech Event and the Function of Language. Oxford: Oxford Up.

Mahsun. 2005. Metode Penelitian Bahasa. Jakarta: PT. Raja Grafindo Persada.

Muslich, Masnur. 2011.Fonologi Bahasa Indonesia. Jakarta: Bumi Aksara.

Sutedi, Dedi. 2003. Dasar-dasar Linguistik bahasa Jepang. Bandung: Humaniora Utama Press (HUP).

Tokieda, Motoki and Kokugo Gakkai.1980. Kokugogakudaijiten. Tokyo: Tokyodo Shuppan 